\title{
Visualisasi Bangunan Peninggalan Belanda di Kotabaru Yogyakarta melalui ESRI Story Map
}

\author{
ANNISA FARIDA, NI PUTU PRAJA CHINTYA, WAHYU MARTA MUTIARASARI
}

\author{
Program Studi Diploma 3 Teknik Geomatika \\ Universitas Gadjah Mada \\ Email: annisa.farida@ugm.ac.id
}

\begin{abstract}
ABSTRAK
ESRI Story map merupakan cara untuk memvisualisasikan peta dan data nonspasial pada aplikasi web tingkat lanjut. Contoh data nonspasial adalah teks narasi, gambar, dan konten multimedia. Salah satu peta cerita yang paling populer adalah peta cerita dalam bentuk jurnal. Peta cerita format jurnal menyajikan lokasi secara visual yang ditambahkan dengan data nonspasial. Makalah ini menyajikan cerita melalui ESRI story map untuk memvisualisasikan bangunan peninggalan Belanda di Kotabaru, Kota Yogyakarta. Bangunan peninggalan Belanda disebut juga sebagai bangunan heritage. Jumlah bangunan Heritage di Kotabaru saat ini menurun karena adanya pertumbuhan ekonomi di Kota Yogyakarta yang mengakibatkan beberapa bangunan heritage berubah menjadi bangunan modern. Jurnal ini menyajikan informasi tentang lokasi bangunan heritage yang disertai narasi sejarahnya sebagai salah satu upaya melestarikan bangunan bersejarah.
\end{abstract}

Kata kunci: Bangunan peninggalan Belanda, peta cerita, spasial, heritage

\begin{abstract}
ESRI story map is an advance way to visualize maps with nonspatial data in a web application. Examples of nonspatial data are narrative text, images, and multimedia context. The most popular story map is story map journal. The story map journal shows nonspatial and the location of the story visually. We made story maps using ESRI story map to visualize Dutch heritage buildings in Kotabaru, Yogyakarta Province. Dutch heritage buildings are known as heritage buildings. Now, the number of heritage building is decreasing. This is due to economic growth in Yogyakarta. There are some significant changes in this area. Some heritage buildings are transformed into modern buildings. This paper presents the location information of heritage buildings along with its historical narrative as one of efforts to preserve the historical buildings.
\end{abstract}

Keywords: Dutch heritage buildings, story map, spatial, heritage 


\section{PENDAHULUAN}

Warisan budaya merupakan rekaman cara hidup yang dibangun oleh komunitas manusia pada saat itu (Kleden dan Fanani, 2017). Warisan budaya mengacu pada monumen, bangunan, dan situs nilai warisan (UNESCO, 2017). Kotabaru merupakan salah satu tempat bersejarah di Kota Yogyakarta. Kotabaru berlokasi di Kecamatan Gondokusuman, Kota Yogyakarta. Berdasarkan Peraturan No. 2 Tahun 2010 tentang RTRWP DIY, kawasan Kotabaru merupakan kawasan budaya dan sejarah (Pemprov DIY, 2010). Pada jaman kolonial, kawasan Kotabaru merupakan kawasan pemukiman masyarakat Belanda. Kotabaru atau disebut sebagai Nieuwe Wijk mulai dibangun pada tahun 1917 dan selesai dibangun pada tahun 1920. Tata ruang kawasan Kotabaru didesain oleh arsitektur Belanda yaitu Ir. Thomas Karsten. Konsep desain tata ruangnya terinspirasi dari konsep kota kebun (garden city) atau dalam bahasa Belanda disebut tuinstaad yang diperkenalkan oleh Ebenezer Howard yaitu seorang arsitektur dari Inggris. Kotabaru mulai dibangun karena perkembangan industri gula dan masyarakat kolonial memiliki ketertarikan untuk meningkatkan kualitas pendidikan dan kesehatan (Kleden dan Fanani, 2017). Pembangunan Kotabaru juga dipengaruhi oleh bertambahnya jumlah penduduk Belanda.

Bangunan peninggalan Belanda atau disebut bangunan heritage terdiri atas bangunan tempat tinggal, rumah sakit, sekolah, kantor, dan lain sebagainya. Seiring perkembangan zaman fungsi bangunan heritage banyak berubah menjadi bangunan perkantoran, kafe, restoran, penginapan, dan sebagainya. Bahkan, sebagian di antaranya dihancurkan dan diganti bangunan baru. Berdasarkan Undang-Undang No.11 Tahun 2010 pasal 19 tentang Cagar Budaya (Republik Indonesia, 2010) dan Peraturan Gubernur Daerah Istimewa Yogyakarta nomor 62 tahun 2013 tentang Pelestarian Warisan budaya disebutkan bahwa pemerintah dan masyarakat wajib menjaga dan memelihara bangunan heritage.

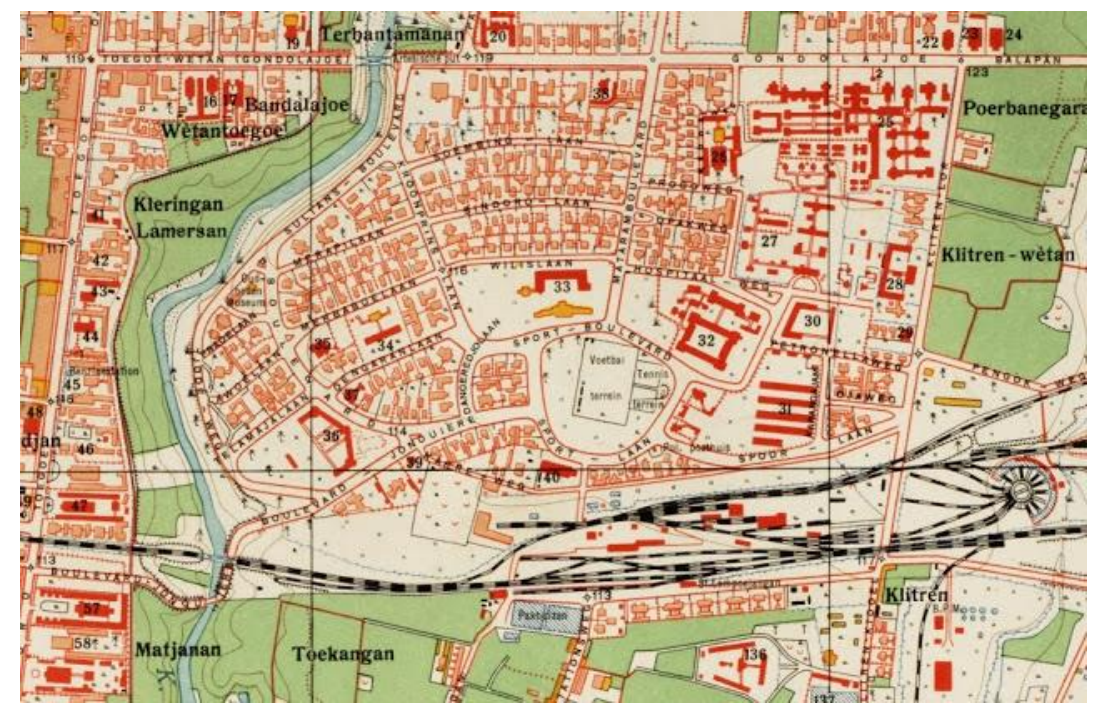

Gambar 1. B/ueprint tata ruang Kotabaru

Terdapat banyak cara untuk melestarikan bangunan heritage. Salah satu caranya adalah memanfaatkan data geospasial. Data geospasial terdiri atas format vektor dan raster. Data geospasial dapat diproduksi dari berbagai sumber data, misalnya citra satelit, foto udara, dan hasil digitasi on-screen. 
Data geospasial menyajikan lokasi objek-objek di permukaan Bumi. Salah satu metode untuk menyajikan lokasi objek di permukaan Bumi adalah melalui visualisasi menggunakan storytelling map (peta dongeng). Storytelling map menyajikan cerita tentang objek-objek di permukaan Bumi yang disertai dengan narasi sejarah atau cerita. Melalui pemanfaatan data geospasial, makalah ini menyajikan storytelling map yang menggabungkan sejarah dan fungsi bangunan heritage di Kotabaru dengan visualisasi data geospasial. Diharapkan bahwa melalui storytelling map ini dapat membantu pemerintah dan masyarakat dalam mengelola dan melestarikan bangunan heritage yang ada di kawasan Kotabaru.

\section{METODOLOGI}

\subsection{Bangunan Peninggalan Belanda di Kotabaru, Kota Yogyakarta}

Kawasan Kotabaru terdiri atas Kecamatan Gondokusuman dan sebagian Kecamatan Danurejan. Detail kawasan Kotabaru dapat dilihat pada Tabel 1. Bangunan heritage di Kotabaru mulai dibangun pada akhir Perang Dunia ke-1 sebagai kompleks perumahan modern yang didedikasikan untuk warga kulit putih pada saat itu (Wibisono dan Ronald, 2014). Kompleks perumahan dibangun khusus untuk pejabat Belanda, seperti administrator pabrik gula di Yogyakarta (Kesuma dan Prayitno, 2013). Model bangunan yang terdapat di Kotabaru merupakan hasil perpaduan akulturasi budaya asing dan budaya lokal. Terdapat berbagai jenis bangunan yang memiliki fungsi berbeda-beda, seperti rumah, sekolah, kantor, tempat ibadah, kompleks perbelanjaan, dan stasiun kereta api. Tabel 2 menyajikan bangunan heritage yang terdapat di Kotabaru berdasarkan kegunaannya.

Wahyu (2011) menyatakan bahwa bangunan di kawasan Kotabaru sebagian besar memiliki karakteristik bangunan era kolonial Belanda. Karakteristik bangunan dapat dilihat melalui proporsi bangunan head-body-foot dan prinsip desain bangunan. Selain itu, ciri khas bangunan pada kawasan Kotabaru terdapat ruang terbuka hijau atau taman diantara bangunan. Kawasan Kotabaru memiliki pola radial dengan ruang hijau yang luas. Terdapat area hijau yang cukup luas di Kotabaru dan dikelilingi dengan jalan raya dengan cukup banyak pohon pada kanan dan kiri jalan.

Pertumbuhan ekonomi penyebabkan perubahan pada kawasan Kotabaru. Banyak bangunan baru dibangun untuk mendukung perekonomian dan jumlah bangunan heritage semakin menurun. Peraturan Daerah nomor 6 tahun 2012 pasal 64 menyatakan bahwa kawasan Kotabaru merupakan salah satu cagar budaya yang perlu dilindungi dan dilestarikan bangunannya. Didalam peraturan tersebut terdapat peraturan yang mengatur arsitektur bangunan yang diperbolehkan untuk dibangun di kawasan Kotabaru. Pembangunan gedunggedung baru harus menggunakan gaya arsitektur belanda (Pemprov DIY, 2012). Namun, regulasi tersebut belum diimplementasikan dengan baik karena masyarakat masih mengabaikan aturan pembangunan gedung baru (Pemprov DIY, 2012).

Tabel 1. Detail kawasan Kotabaru (Ulfia dan Kleden, 2011)

\begin{tabular}{ccll}
\hline No & Kawasan & \multicolumn{1}{c}{ Batas wilayah } \\
\hline \multirow{2}{*}{1} & Kawasan utama & Utara & Jalan Jenderal Sudirman \\
\cline { 3 - 4 } & & Selatan & Rel keretaapi \\
\cline { 3 - 4 } & & Barat & Sungai Code \\
\cline { 3 - 4 } & & Timur & Jalan Wahidin Sudirohusodo \\
\hline 2 & Kawasan & Utara & Jalan Cik Di Tiro \\
\cline { 3 - 4 } & pendukung & Selatan & Jalan Stasiun Lempuyangan - Rel kereta api \\
\cline { 3 - 4 } & Barat & Jalan C. Simanjuntak \\
\cline { 3 - 3 } & Timur & Jalan Dr. Sutomo \\
\hline
\end{tabular}


Tabel 2. Bangunan peninggalan Belanda di Kotabaru (Ulfia dan Kleden, 2011)

\begin{tabular}{|c|c|c|c|}
\hline No & Kegunaan & $\begin{array}{l}\text { Nama Bangunan Peninggalan } \\
\text { Belanda }\end{array}$ & Nomor Surat Keputusan \\
\hline \multirow[t]{9}{*}{1} & \multirow[t]{9}{*}{ Pendidikan } & SD Negeri Ungaran I & BCB PM.07/PW.007/MKP 2007 \\
\hline & & SMP Negeri 5 & BWB 798/KEP/2009 \\
\hline & & SMA Negeri 3 & BCB PM.07/PW.007/MKP 2007 \\
\hline & & SMA Bopkri 1 & BCB PM.07/PW.007/MKP 2007 \\
\hline & & SMP Negeri 8 & BCB 210/KEP/2010 \\
\hline & & SMA Negeri 6 & BCB PM.07/PW.007/MKP2010 \\
\hline & & SMA Negeri 9 & BWB 798/KEP/2009 \\
\hline & & SMP Negeri 1 & BCB PM.07/PW.007/MKP/2010 \\
\hline & & Museum TNI AD & BCB 210/KEP/2010 \\
\hline \multirow[t]{4}{*}{2} & \multirow[t]{4}{*}{ Kesehatan } & RS Panti Rapih & BCB PM.07/PW.007/MKP2010 \\
\hline & & RS Mata dr. YAP & BCB PM.07/PW.007/MKP 2007 \\
\hline & & RS Bethesda & BCB 210/KEP/2010 \\
\hline & & RS DKT & BCB 210/KEP/2010 \\
\hline \multirow[t]{2}{*}{3} & \multirow[t]{2}{*}{ Tempat ibadah } & Gereja St Antonius & BCM PM.07/PW.007/MKP2010 \\
\hline & & Gereja HKBP & BCM 210/KEP/2010 \\
\hline \multirow[t]{6}{*}{4} & \multirow{6}{*}{$\begin{array}{l}\text { Peradangan dan } \\
\text { layanan }\end{array}$} & Indraloka Homestay & BWB 798/KEP/2009 \\
\hline & & EMX Fortune Int & BWB 798/KEP/2009 \\
\hline & & Gabah Resto & BWB 798/KEP/2009 \\
\hline & & Kafe dan Resto Own Cipta Karya & BWB 798/KEP/2009 \\
\hline & & Pizza Hut & BCB 210/KEP/2010 \\
\hline & & Gedung Asuransi Jiwasraya & BWB 798/KEP/2009 \\
\hline \multirow[t]{16}{*}{5} & \multirow[t]{16}{*}{ Perumahan } & Rumah Tinggal 1 & BWB 798/KEP/2009 \\
\hline & & Rumah Tinggal 2 & BWB 798/KEP/2009 \\
\hline & & Rumah Tinggal 3 & BWB 798/KEP/2009 \\
\hline & & Rumah Tinggal 4 & BWB 798/KEP/2009 \\
\hline & & Rumah Tinggal 5 & BWB 798/KEP/2009 \\
\hline & & Rumah Tinggal 6 & BWB 798/KEP/2009 \\
\hline & & Rumah Tinggal 7 & BWB 798/KEP/2009 \\
\hline & & Rumah Tinggal 8 & BWB 798/KEP/2009 \\
\hline & & Rumah Tinggal 9 & BWB 798/KEP/2009 \\
\hline & & Joglo Mangun Suwito / Surono & BWB 798/KEP/2009 \\
\hline & & Susteran Amal Kasih Mulia & BCB 185/KEP/2011 \\
\hline & & Seminari & BCB 210/KEP/2010 \\
\hline & & Kolose St Ignatius & BCB 210/KEP/2010 \\
\hline & & Asrama Mahasiswa Aceh & BWB 798/KEP/2009 \\
\hline & & Asrama Kompi & BCB 210/KEP/2010 \\
\hline & & $\begin{array}{l}\text { Asrama Mahasiswa Putri } \\
\text { Ratnaningsih }\end{array}$ & BWB 798/KEP/2009 \\
\hline \multirow[t]{3}{*}{6} & \multirow[t]{3}{*}{ Kantor } & RRI & BCB 210/KEP/2010 \\
\hline & & $\begin{array}{l}\text { Badan Perpustakaan } \\
\text { Daerah }\end{array}$ & BCM PM.07/PW.007/MKP2010 \\
\hline & & $\begin{array}{l}\text { Dinas Kebudayaan dan } \\
\text { Pariwisata Kota }\end{array}$ & BCM PM.07/PW.007/MKP2010 \\
\hline 7 & Transportasi & Stasiun Lempuyangan & BCB 210/KEP/2010 \\
\hline
\end{tabular}




\subsection{Esri Story Maps}

Storytelling map merupakan metode tingkat lanjut untuk menyampaikan pesan pada pengguna secara langsung berbasis geospasial (Kirkby dkk., 2014). Storytelling map berisi tentang cerita yang di dalamnya terdapat peta (informasi geospasial) atau data geospasial dan narasi cerita dibuat bertujuan untuk menyampaikan masalah, menyebarkan pengetahuan, dan sebagainya (Bowden dkk., 2016).

Peta dapat dimanfaatkan sebagai media untuk menyampaikan informasi geospasial tentang dunia nyata (Strachan, 2014). Peta memiliki kemampuan untuk menceritakan kisah tentang dunia nyata, hubungan objek di dunia nyata sepanjang waktu (Marta dan Osso, 2015). Peta dapat diperkaya dengan memanfaatkan berbagai media dan narasi untuk menyajikan informasi secara interaktif. Contoh aplikasi untuk menyajikan cerita yang dilengkapi dengan peta dan berbagai media dan narasi adalah ESRI Story Map (Sohn, 2016). Esri Story Maps adalah aplikasi sistem informasi geospasial (SIG) berbasis web yang dikembangkan oleh ESRI menggunakan platform ArcGIS Online. Esri Story Map mampu menceritakan sebuah cerita berbasis lokasi.

Storytelling map memiliki berbagai template yang dapat dipilih sesuai dengan tujuannya. Contoh template dari peta cerita adalah Story Map Tour, Story Map Journal, dan Story Map Cascade. Story Map Tour digunakan untuk menyajikan foto atau video yang terhubung secara interaktif pada peta. Template ini cocok untuk mengunjungi dari satu lokasi ke lokasi lain dan dapat melihat foto atau video yang terkait secara interaktif dari lokasi tersebut. Story Map Journal umumnya digunakan untuk menyajikan narasi yang dibagi menjadi bagian-bagian tertentu. Story Map Cascade mirip dengan Story Map Journal. Perbedaannya ada pada tampilan layout. Narasi dan media ditampilkan dalam satu layar penuh seperti tampilan blog. Pengguna dapat menikmati konten dengan menggulir halaman storytelling map.

Esri Story Maps dapat digunakan untuk berbagai aplikasi, seperti pendidikan, ekonomi, lingkungan, geologi, bahaya, dan antropologi. Salah satu contoh peta cerita adalah 'Keanekaragaman hayati hutan bakau untuk Proyek Aksi Mangrove (MAP)'. Contoh lainnya dapat ditemukan pada situs web Esri Story Maps.

\subsection{Produksi dan Pengolahan Data}

Data yang diperlukan untuk membuat storytelling map bangunan heritage adalah peta dasar, data vektor, foto, dan data atribut (nama, kategori, dan narasi bangunan Heritage). Data vektor dihasilkan dari proses digitalisasi citra satelit Quickbird. Fitur-fitur digital adalah batasbatas wilayah Kotabaru dan titik-titik lokasi bangunan heritage. Data luasan dan titik disimpan dalam format geojson berdasarkan pada format peta cerita.

Foto-foto terbaru dari bangunan heritage diperoleh dengan mengambil gambar langsung di lapangan dan dari sumber internet resmi, misalnya situs web perpustakaan Leiden. Adapun naskah sejarah diperoleh dari berbagai sumber terpercaya seperti situs dinas pariwisata dan kebudayaan dan situs web perpustakaan Lieden. Data yang disiapkan (data vektor, foto, dan sejarah bangunan heritage) diunggah ke dalam template peta cerita. Template yang digunakan untuk menyajikan cerita bangunan heritage di Kotabaru adalah Story Map Journal. Lokasi bangunan heritage disajikan dalam simbol titik dari foto-foto geotag. Kisahkisah sejarah bangunan dan foto-foto warisan ditampilkan pada halaman sidebar storytelling map. 


\section{HASIL DAN PEMBAHASAN}

Hasil dari penelitian ini adalah storytelling map yang berjudul "Tracing Europe through Heritage Buildings in Kotabaru, Yogyakarta". Template yang digunakan untuk membuat storytelling map pada penelitian ini adalah Story Maps Journal. Secara umum, storytelling map berisi lokasi bangunan, foto-foto bangunan dan narasi sejarah bangunan heritage, serta pemanfaatannya saat ini. Template, foto, dan tata letak pada halaman storytelling map dirancang agar menarik perhatian pengguna terhadap sejarah bangunan heritage di Kotabaru. Storytelling map ini dirancang sebagai platform untuk menyajikan sejarah bangunan cagar budaya.

Gambar 2 adalah halaman beranda atau home page. Halaman beranda menampilkan batas wilayah Kotabaru yang divisualisasikan dengan poligon berwarna putih. Visualisasi ini akan membuat pengguna fokus pada kawasan Kotabaru dan membantu pengguna untuk mengidentifikasi batas dan cakupan area. Bangunan heritage divisualisasikan dengan menggunakan simbol piktorial. Simbol piktorial menyajikan obyek di permukaan Bumi dalam bentuk titik pada peta yang mirip dengan objek aslinya. Penyajian lokasi bangunan heritage dalam simbol piktorial akan membantu pengguna mengenali bangunan heritage berdasarkan kriteria pemanfaatan bangunan. Daftar pemanfaatan bangunan heritage yang disajikan pada Gambar 2. Jumlah bangunan heritage yang disajikan pada storytelling map ini adalah 27 bangunan dari 41 bangunan (berdasarkan Tabel 2). Hal tersebut disebabkan oleh beberapa alamat atau lokasi bangunan heritage yang tidak diketahui selama survei lapangan.

Bagian selanjutnya dari storytelling map adalah narasi dari setiap bangunan yang dilengkapi dengan lokasinya di sebelah kanan serta dilengkapi foto terbaru dari bangunan heritage. Bagian halaman peta tersebut ditunjukkan pada Gambar 3. Dengan demikian, pengguna dapat mengetahui lokasi, kondisi, dan sejarah bangunan heritage yang berada di kawasan Kotabaru. Peta heritage dapat digunakan sebagai panduan untuk tour studi langsung atau hanya melalui situs web.
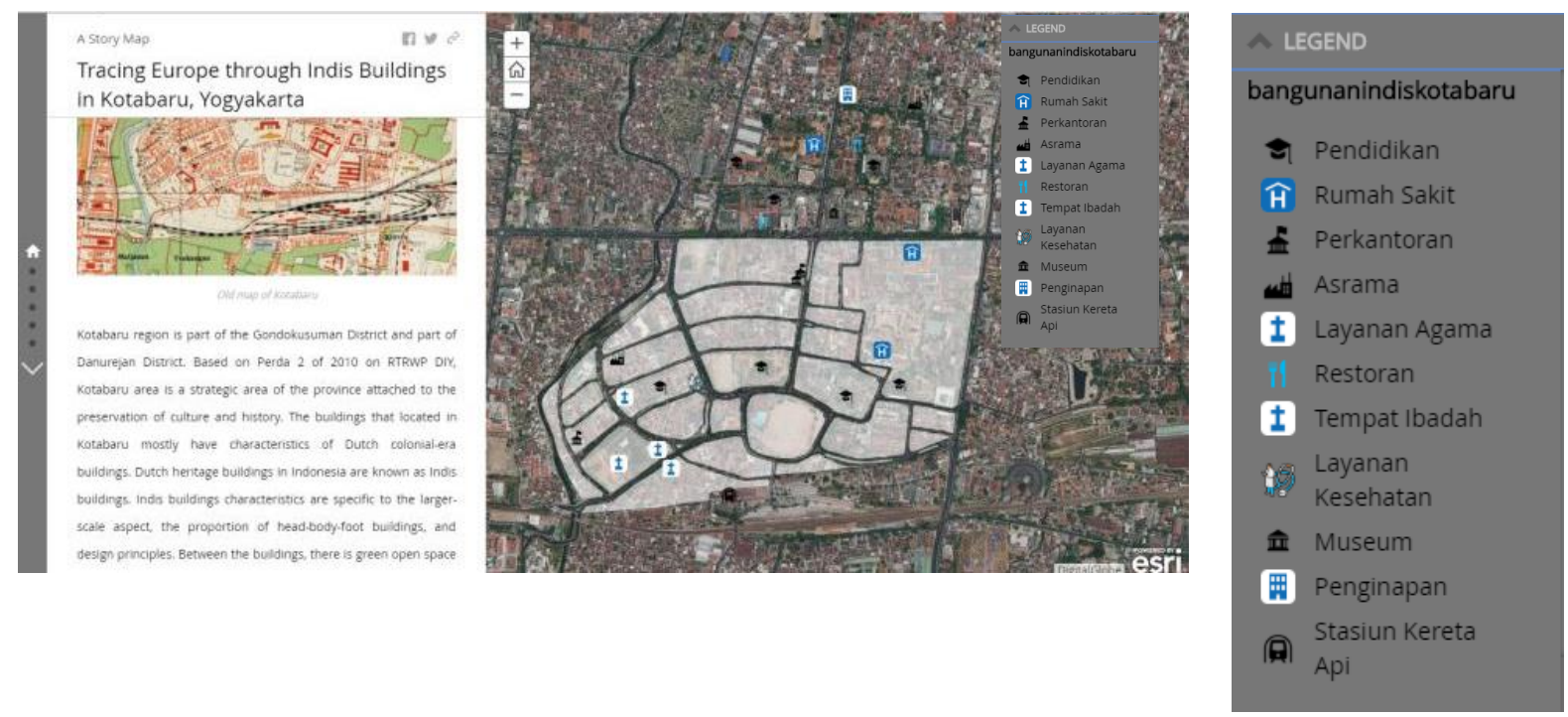

Gambar 2. Sejarah bangunan di Kotabaru disajikan pada halaman storytelling map 

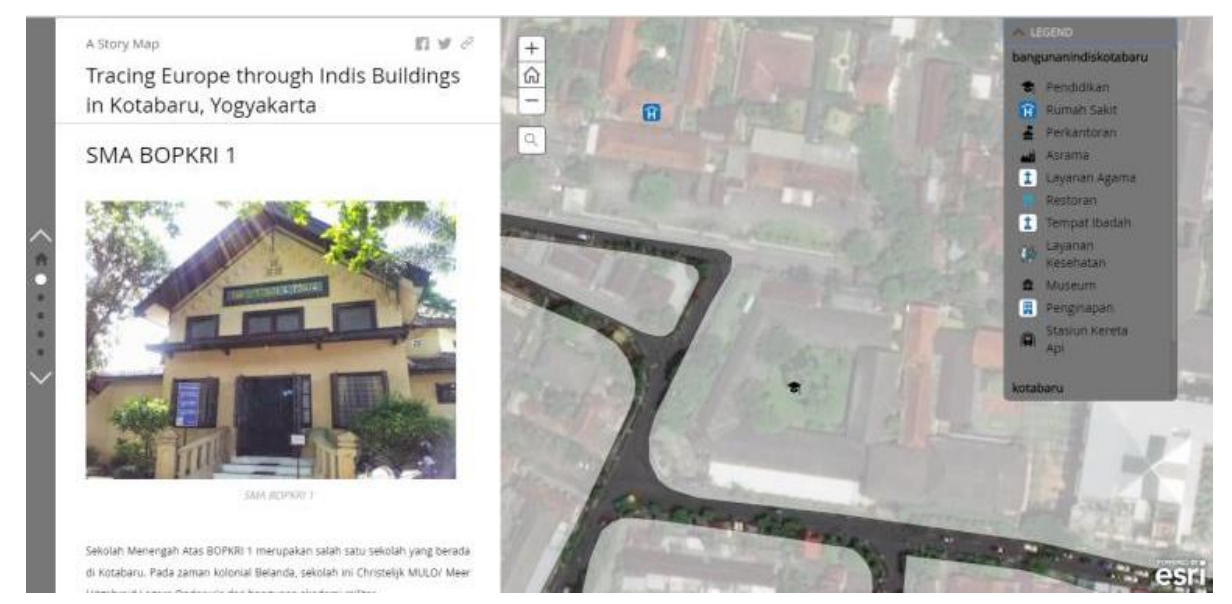

Gambar 3. Sejarah bangunan SMA BOPRKI 1 Kotabaru

Berdasarkan storytelling map, terdapat beberapa informasi tentang kondisi bangunan heritage saat ini. Beberapa kondisi bangunan masih bagus dan digunakan untuk fungsi baru tanpa mengubah arsitektur bangunan. Selain itu, terdapat bangunan yang sudah berubah menjadi bangunan yang lebih modern. Misalnya, pembangunan kafe yang mengikuti gaya modern dan menghancurkan bangunan tua. Adanya pemugaran pada bangunan heritage berarti bahwa peraturan yang terkait dengan pelestarian warisan budaya sebagian besar diabaikan. Bangunan yang diubah ini ditunjukkan pada Gambar 4.

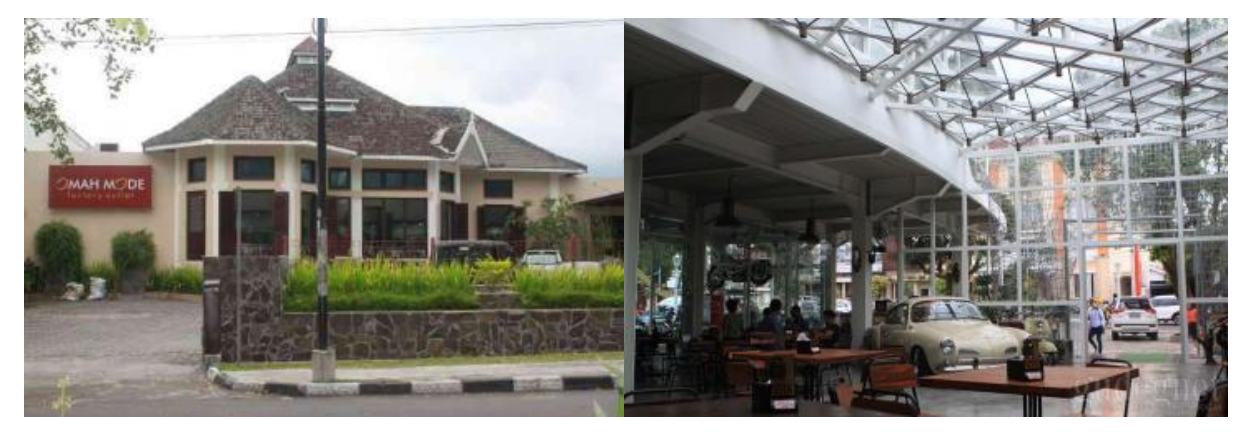

Gambar 4. Bangunan heritage sebelum dan setelah renovasi menjadi bangunan modern

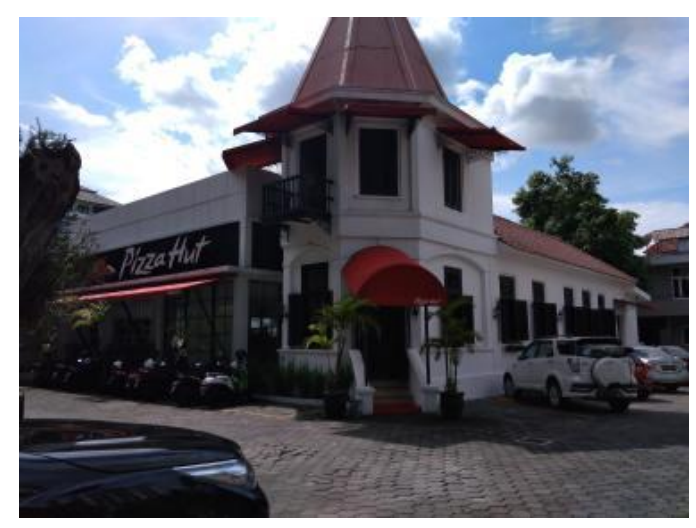

Gambar 5. Pemanfaatan bangunan heritage untuk perdagangan 
Pada penelitian ini, dilakukan analisis terhadap 41 bangunan heritage berdasarkan segi pemanfaatannya. Berdasarkan Tabel 2, terdapat 15 bangunan yang digunakan untuk perdagangan atau jasa, 14 bangunan digunakan untuk bangunan pribadi, 1 bangunan tempat ibadah, 2 bangunan fasilitas kesehatan, 4 bangunan untuk fasilitas pendidikan, 3 gedung digunakan sebagai kantor, dan 1 bangunan transportasi. Gambar 5 adalah contoh bangunan heritage yang terdapat di kawasan di Kotabaru. Penelitian ini mengungkap bahwa terdapat enam (6) bangunan heritage yang telah berubah pemanfaatannya dan sepuluh (10) bangunan heritage yang tidak diketahui pemanfaatannya di masa lalu dan sisanya tidak berubah pemanfaatannya. Daftar perubahan bangunan heritage disajikan pada Tabel 3 di bawah ini.

Tabel 3. Bangunan Heritage yang telah berubah kegunaannya

\begin{tabular}{clcc}
\hline Nomor & \multicolumn{1}{c}{ Bangunan Heritage } & $\begin{array}{c}\text { Pemanfaatan } \\
\text { zaman dahulu }\end{array}$ & $\begin{array}{c}\text { Pemanfaatan saat } \\
\text { ini }\end{array}$ \\
\hline 1 & Museum TNI AD & Tempat tinggal & Museum \\
\hline 2 & Gereja HKBP & Gereja, Masjid & Gereja \\
\hline 3 & Indraloka homestay & Tempat tinggal & Penginapan \\
\hline 4 & Susteran Amal Kasih Mulia & Tempat tinggal & Susteran \\
\hline 5 & RRI & $\begin{array}{c}\text { Tempat tinggal, } \\
\text { Kantor }\end{array}$ & Kantor RRI \\
\hline 6 & Badan Perpustakaan Daerah & Kantor & Museum \\
\hline 7 & EMX Fortune Int & Tidak diketahui & Restoran \\
\hline 8 & Gabah Resto & Tidak diketahui & Restoran \\
\hline 9 & Kafe dan Resto Own Cipta Karya & Tidak diketahui & Restoran \\
\hline 10 & Pizza Hut Sudirman & Tidak diketahui & Restoran \\
\hline 11 & Joglo Mangun Suwito / Surono & Tidak diketahui & Tempat tinggal \\
\hline 12 & Seminari & Tidak diketahui & Seminari \\
\hline 13 & Asrama Mahasiswa Aceh & Tidak diketahui & Asrama \\
\hline 14 & Asrama kompi & Tidak diketahui & Asrama \\
\hline 15 & Asrama Mahasiswa Putri Ratnaningsih & Tidak diketahui & Asrama \\
\hline 16 & Dinas Kebudayaan dan Pariwisata & Tidak diketahui & Kantor \\
\hline
\end{tabular}

\section{KESIMPULAN}

Storytelling map bangunan peninggalan Belanda di Kotabaru terinspirasi dari storytelling map yang terdapat pada ESRI Story map. Storytelling map ini menceritakan tentang sejarah bangunan heritage di Kotabaru dan pemanfaatannya saat ini. Kotabaru adalah salah satu kawasan bersejarah di Yogyakarta, sehingga kawasan Kotabaru harus dilestarikan. Adanya storytelling map ini dapat dimanfaatkan pengguna untuk menikmati sejarah Eropa yang ada di Kotabaru melalui situs web.

Penyajian sejarah bangunan peninggalan Belanda di Kotabaru yang melibatkan unsur geospasial dan skrip cerita sederhana membantu pengguna memahami sejarah dan tidak jenuh membaca skrip sejarah yang panjang. Peta halaman cerita disajikan sederhana, sehingga pengguna dapat melihat sejarah setiap bangunan peninggalan Belanda dengan cara menggulir halaman ke bawah.

Hasil dari pembuatan storytelling map yang berjudul "Tracing Europe through Heritage Buildings in Kotabaru, Yogyakarta" ini diharapkan dapat berkontribusi pada sektor pariwisata yaitu untuk membantu menyebarkan pengetahuan tentang sejarah bangunan heritage di Kotabaru. Dari sisi pelestarian bangunan cagar budaya, storytelling map ini diharapkan dapat 
membantu pemerintah Kota Yogyakarta dan masyarakat mengetahui lokasi dan sejarah bangunan peninggalan Belanda untuk membantu impementasi Peraturan Daerah nomor 6 tahun 2012 tentang Pelestarian Warisan Budaya dan Cagar Budaya.

\section{DAFTAR PUSTAKA}

Bowden, K.K., Lin, G.I., Reed, L.I., Tree, J.E.F., dan Walker, M.A. (2016). M2d: Monolog to dialog generation for conversational storytelling, in International Conference on Interactive Digital Storytelling, pp. 12-24.

Kesuma, Y. dan Prayitno, B. (2013). Karakter Visual Kawasan Kotabaru, Yogyakarta Berdasarkan Konsep Garden City, Universitas Gadjah Mada.

Kirkby, J., Faulkner, J., dan Perrin., J. (2014). 'Once there was a...': Reclaiming storytelling in the middle years. Lit. Learn. Middle Years, vol. 22, no. 2.

Kleden, U. C. dan Fanani, F. (2017). Harmonisasi Ketentuan Peruntukan Bangunan Cagar Budaya Dalam Perspektif Regulasi Di Kawasan Budaya Kotabaru, Kota Yogyakarta-DIY, Pros. Semin. Nas. ReTII, Vol. 0, No. 0.

Marta, M. dan Osso, P. (2015). Story Maps at school: teaching and learning stories with maps, J-Reading-Journal Res. Didact. Geogr., vol. 2, no. 4, pp. 61-68.

Pemerintah Provinsi Daerah Istimewa Yogyakarta (Pemprov DIY). (2010). Peraturan Daerah Provinsi DIY Nomor 2 Tahun 2010 tentang Rencana Tata Ruang Wilayah Provinsi DIY Tahun 2009-2029." Yogyaka, pp. 1-64.

Pemerintah Provinsi Daerah Istimewa Yogyakarta (Pemprov DIY). (2012). Peraturan Daerah Provinsi Daerah Istimewa Yogyakarta Nomor 6 Tahun 2012 Tentang Pelestarian Warisan Budaya Dan Cagar Budaya. Pemerintah Provinsi Daerah Istimewa Yogyakarta, Yogyakarta, p. 30.

Republik Indonesia (2010). Undang-Undang No. 11 tahun 2010 tentang Cagar Budaya. Jakarta, 2010.

Sohn, M. (2016). Species Richness Maps and Esri Story Maps for the biodiversity of mangrove forest for the Mangrove Action Project (MAP), Issue: August.

Strachan, C. (2014). Teachers Perceptions of Esri Story Maps as Effective Teaching Tools, University of South Carolina.

Ulfia, F.F. dan Kleden, C. (2011). Cagar Budaya Dalam Perspektif Regulasi, no. 11, pp. 167177.

United Nations Educational Scientific and Cultural Organization (UNESCO) (2018). Tangible Cultural Heritage, [Online]. Dipetik dari http://www.unesco.org/new/en/cairo/culture/tangible-cultural-heritage/.

Wahyu, H.T. (2011). Pelestarian dan Pemanfaatan Bangunan Indis di Kawasan kotabaru. Tesis. Yogyakarta: Universitas Gadjah Mada.

Wibisono, T. dan Ronald, D. (2014). Ciri-Ciri Bangunan Rumah Indis di Kotabaru Yogyakarta. 